\title{
Anotaciones sobre el Ph, Herbivoria y Apertura Estomática, en las hojas de Rhizophora harrisonii en dos Zonas del Golfo de Guayaquil
}

Notes on the Ph. Herbivory and Stomatic Opening, in the leaves
of Rhizophora harrisonii in two Areas of the Gulf of Guayaquil

Olga Quevedo Pinos ${ }^{1, *}$, Bladimir Jaramillo Escobar ${ }^{2}$, Willan Revelo Ramirez ${ }^{3}$

INFORMACIÓN DEL

ARTÍCULO

Fecha de recepción: 20 de diciembre de 2019.

Fecha de aceptación: 29 de febrero de 2020 .

\footnotetext{
${ }^{1}$ Universidad de Guayaquil, Facultad de Ingeniería Química. Ciudadela Salvador Allende, Av. Delta y Av. Kennedy, Guayaquil - Ecuador.

Email: olga.quevedop@ug.edu.ec.
}

${ }^{2}$ Universidad de Guayaquil, Facultad de Comunicación Social. Ciudadela Salvador Allende, Av. Delta y Av. Kennedy, Guayaquil - Ecuador

Email: bladimir.jaramilloe@ug.edu.ec.

Instituto Nacional de Pesca. Letamendi 210 y la Ría, Guayaquil Ecuador.

Email: wrevelo@institutopesca.gob.ec.

* Autor de correspondencia:

Olga Quevedo Pinos. Universidad de Guayaquil, Facultad de Ingeniería Química.

Email: olga.quevedop@ug.edu.ec.

Tlf.:(593-5) 2685-609.

https://orcid.org/0000-0002-0250-9228

ENLACE DOI:

http://dx.doi.org/10.31095/investigatio. 2020.13.11

\section{Resumen}

Se avaluó el daño foliar de Rhizophora harrisonii en las Islas Trinitaria y Chupador Chico del Golfo de Guayaquil, durante las épocas: seca y lluviosa, 2016- 2017 usando el software Creative Cloud del programa Adobe Photoshop Extended para la medición del daño foliar por necrosis, clorosis y ramoneo provocado por Thyrinteina arnobia Stoll. Así como también el índice estomático, y el pH. Se empleó ANOVA simple de una vía y se validaron con el test de Kruskal Wallis para muestras no paramétricas. Se encontró que el $40 \%$ de las muestras colectadas en la Isla Trinitaria están afectadas, no así el manglar de Chupador Chico, donde no se encontró la presencia de Thyrinteina. Las diferencias temporales sobre los daños foliares se intensifican durante la época seca, se considera que su presencia respondió a un comportamiento de plaga, que se disparó por las condiciones ambientales anormales que se presentaron en esa época.

\section{Palabras Clave:}

Rhizophora; Photoshop; necrosis; clorosis; Thyrinteina.

Clasificación JEL: Q20.

\begin{abstract}
Rhizophora harrisonii foliar damage was assessed in the Trinitarian and Chupador Chico Islands of the Gulf of Guayaquil, during the dry and rainy seasons, 2016-2017 using the Creative Cloud software of the Adobe Photoshop Extended program for the measurement of foliar damage by necrosis, chlorosis and browsing caused by Thyrinteina arnobia Stoll. As well as the stomatic index, and the $\mathrm{pH}$. Simple one-way ANOVA was used and they were validated with the Kruskal Wallis test for non-parametric samples. It was found that $40 \%$ of the samples collected on the Trinitarian Island are affected, but not the mangrove of Chupador Chico, where the presence of Thyrinteina was not found. Temporary differences on leaf damage intensify during the dry season, its presence is considered to have responded to a pest behavior, which was triggered by the anormal environmental conditions that occurred at that time.
\end{abstract}

Keywords:

Rhizophora, photoshop, necrosis, chlorosis, thyrinteina.

JEL Classification: Q20. 


\section{Introducción}

La afectación a los ecosistemas de bosques por insectos defoliadores $\mathrm{y}$ barrenadores, son una respuesta a las presiones actuales como el cambio climático, la sequía extrema, o la conjugación de sistemas forestales y el desarrollo urbanístico (Dobbs et al. 2018). Un ataque de insectos puede provocar respuestas como retoñar inmediatamente o al siguiente año, estos disturbios varían espacial y temporalmente, el comprender esta dinámica permite predecir cambios futuros (Senf, Seidl \& Hostert 2017) en los ecosistemas forestales. Casos de herbivoría y cambios en las concentraciones de minerales vinculados con la calidad de las hojas de bosques naturales y plantados fueron analizados por (Giraldo \& Ramírez 2009), quienes concluyeron que la afectación a los tres bloques de bosques estudiados correspondieron al mismo género de insectos.

En el 2000, (Jumbo) hace por primera vez la descripción biológica de Thyrinteina arnobia Stoll (Lepidoptera, Geometridae) como elemento plaga de Rhizophora harrisonii, describiéndo todo su ciclo biológico y comportamiento defoliador que invadió con sus ovoposiciones las paredes de las edificaciones de la ciudad de Guayaquil, colindantes con el Estero Salado; en el Ecuador (Bodner et al. 2010) reportó 59 especies de la familia Geometridae colectadas en los bosques lluviosos montañosos entre los $1800-2800 \mathrm{~m} \mathrm{de}$ altura en la zona andina.
El estudio se realizó en dos sitios del Golfo de Guayaquil, que mantiene una superficie aproximada de 150.000 has. de manglar (CLIRSEN \& PMRC 2006), con un área mejor conservada la Isla Chupador Chico que se encuentra dentro del Humedal Estuarios del Interior del Golfo de Guayaquil (Carvajal \& Salas, 2012), y la segunda la Isla Trinitaria en el Estero Salado, que rodea el sur oeste de la ciudad de Guayaquil, donde la alta actividad vehicular y naviera, así como las emisiones del sector industrial se visibilizan como gruesas capas de hollín sobre las hojas que están expuestas al intercambio gaseoso, el amarilla miento de las hojas (clorosis), manchas negras o marrones (necrosis) y el ataque de insectos cuando estas se presentan más vulnerables, en el Estero Salado de Guayaquil.

El uso de métodos indirectos como la captura de imágenes y su procesamiento digital para la determinación de la superficie foliar son registros que han sido escasamente reportados como elementos de análisis de una problemática vinculada con la deposición ácida y herbivoría. (Sandrini-Neto et al. 2007a), utilizaron Adobe Photoshop para medir daños provocados por insectos en hojas de manglar. La regresión lineal como elemento de medición de las hojas aplicada por Pentón et al. (2006), concluyeron que existe una alta correlación entre las mediciones lineales y el área foliar, superior a $\mathrm{R} 2=0,99$, hace que este procedimiento sea apropiado para la estimación en plantas jóvenes de morera. 
Cerón et al. (2009) demostraron que el mangle y otras especies maderables en Campeche - México, presentan manchas de color café o naranja como señal de necrosis o muerte celular cuando se atomizan con ozono. Así mismo Sauceda Acosta et al., (2015), reportaron a nivel de afectación en los propágulos de Rhizophora harrisonii por Poecilips rhizophorae (Coleóptera: Scolytidae).

Robertson A. J. , R. Giddins, \& Smith, (1990) demostraron que la viabilidad de las semillas y el crecimiento de los propágulos de manglar son afectados por insectos barrenadores en doce especies de manglar, y (Minchinton \& Dalby-Ball, 2001) documentaron que las larvas de Euphranta marina (mosca de la fruta) y Cenoloba obliteralis consumieron los cotiledones de las frutas de Avicennia marina en Australia.

(Guerrero, Quintero \& Naranjo 2012) mencionan que la flexibilidad de los

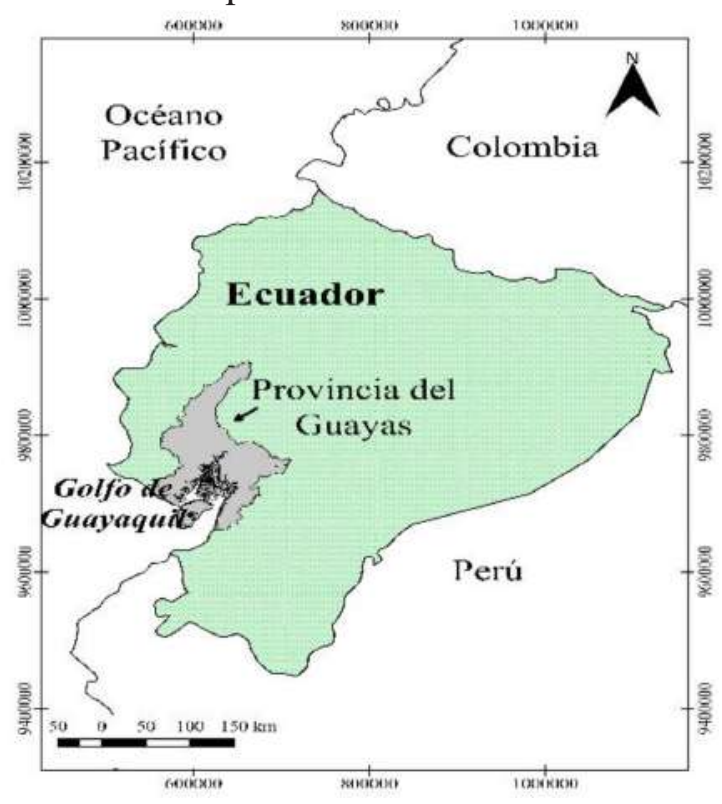

Figura 1. Ubicación geográfica del área de estudio. programas permiten utilizar imágenes en diferentes formatos de archivo de lecturas de mapa de bits, y analizarlos desde softwares libres como Image, también se puede utilizar software profesional como Adobe Photoshop CS2, versión 9 (Sandrini-Neto et al., 2007b) en esta investigación se utilizó la versión Creative Cloud, con Photoshop Extended, el cual contiene herramientas avanzadas para análisis de datos de imágenes, se utilizó en la presente investigación para calcular el daño foliar de las hojas colectadas.

Esta investigación demostrará la calidad de las hojas de Rhizophora harrisonii en dos Islas Chupador Chico e Isla Trinitaria, a partir de la relación de la apertura estomática durante las épocas seca y lluviosa, se determinó el nivel de herbivoría en las hojas de manglar afectadas por la presencia de Thyrinteina arnobia Stoll, y el $\mathrm{pH}$ de las hojas como indicador de acidez.

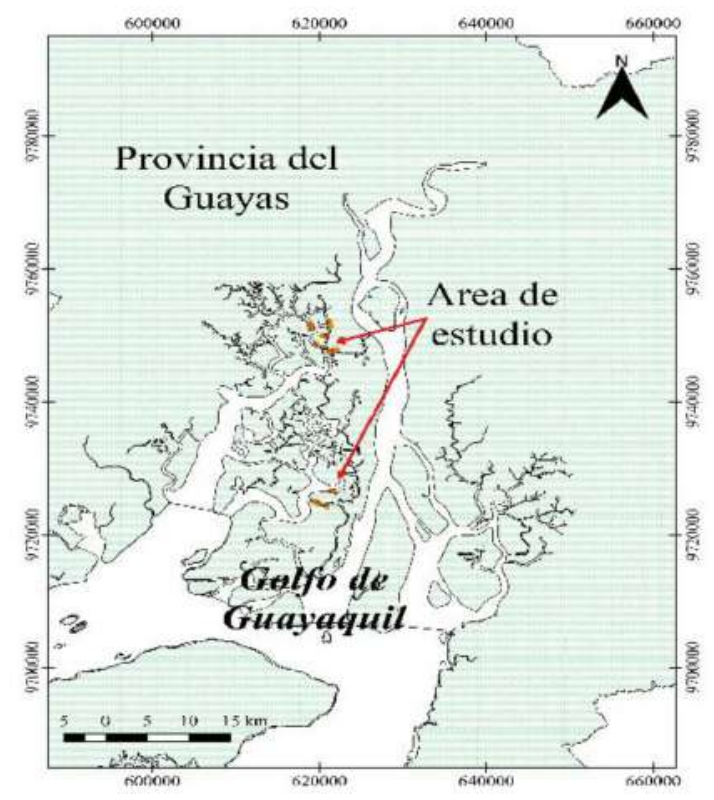




\section{Materiales y métodos}

El estudio se desarrolló en dos islas, La Trinitaria y Chupador Chico de la comunidad Cerrito de Los Morreños del estuario interior del Golfo de Guayaquil (Fig. 1), la primera en el área de influencia del Puerto Marítimo de Guayaquil, cómo área afectada y la segunda como control, por ser la mejor conservada ambientalmente.

En la Tabla 1, se presentan las coordenadas donde se colectaron muestras durante dos épocas seca y lluviosa: agosto-septiembre 2016 y enero-febrero 2017, respectivamente considerando a los meses más extremos con precipitaciones de hasta $800 \mathrm{~mm}$ mensuales solo para Guayaquil, y el ingreso de los vientos alisios del sur-oeste con velocidades máximas de hasta $8 \mathrm{~m} / \mathrm{s}$, respectivamente, Instituto Nacional de
Meteorología e Hidrología (INAMHI 2018).

Tabla 1

Coordenadas geográficas

\begin{tabular}{ccc}
\hline ID & $X$ & $Y$ \\
\hline 1 & 620534 & 9750009 \\
2 & 620468 & 9749935 \\
3 & 620801 & 9749832 \\
4 & 619311 & 9725045 \\
5 & 619666 & 9724755 \\
6 & 619924 & 9724622 \\
\hline
\end{tabular}

En las islas "Trinitaria" (1) y "Chupador Chico" (4) se definieron un total de tres transectos en cada una, con una superficie de $0.50 \mathrm{~m} \times 100 \mathrm{~m}$ (Fig. 2), modificado a partir de Kaufman et al., (2013), en total se colectaron 360 hojas de manera aleatoria, expuestas a los rayos solares y más próximas a la parte superior de las copas de los árboles a las que se llamó "hojas de sol", el acceso a los árboles se hizo siempre desde embarcaciones de madera (canoas) durante la marea alta.

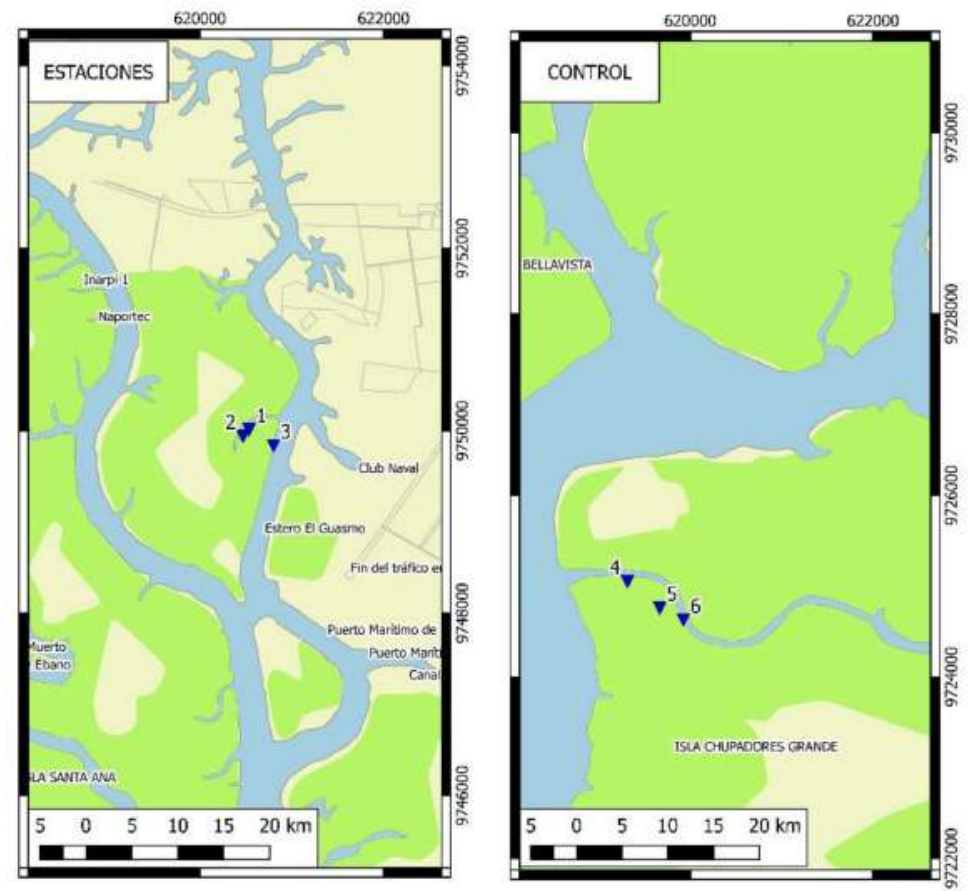

Figura 2. Sitios de muestreos durante la época seca y lluviosa.

118 
La identificación de la especie Rhizophora harrisonii se fundamentó en los estudios contratados por el Ministerio del Ambiente (Ecobiotec 2012) sobre la densidad de esta especie en la Isla Trinitaria, donde identificaron las estaciones 15, 14 y 40 en Isla Trinitaria. En el caso de la Isla Chupador Chico los árboles de Rhizophora harrisonii fueron identificados un año antes de manera previa en base a su floración, con el estudio: Relación de las características morfológicas de Rhizophora harrisonii, con las concentraciones de $\mathrm{SO} 2$ en el área de Influencia del Puerto de Guayaquil.

\section{Colecta de muestras}

Se colectaron cinco hojas de la parte alta de los árboles, que están más expuestas a la intensidad lumínica, a las que se denominó "hojas de sol", la colecta

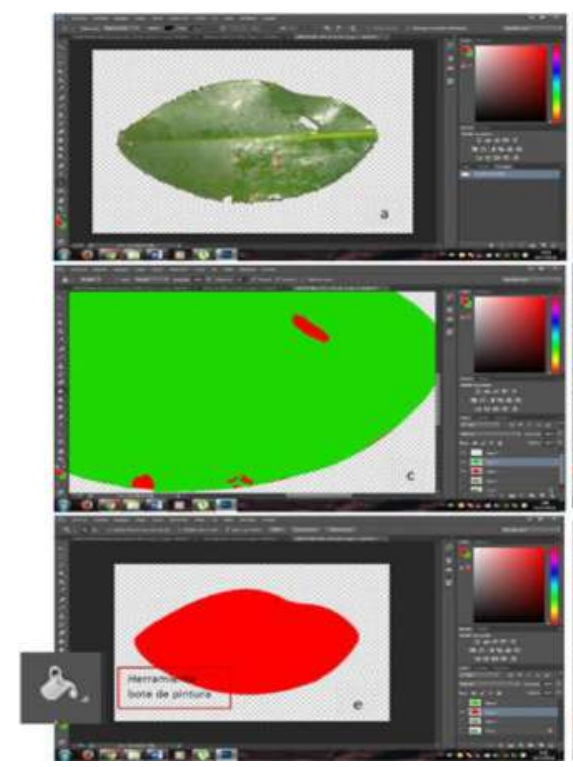

Figura 3. Procesamiento de las hojas de Rhizophora harrisonii con Adobe Photoshop: a) Seleccionar la hoja con la herramienta "Varita Mágica"; b) Crear otra capa creada y pintar con la herramienta bote de pintura esos espacios en color rojo; c) Seleccionar la capa de la hoja (capa 1) e indicar las tres capas pintadas en su respectivo orden; d) Elegir la opción histograma; e) Seleccionar la hoja (capa 1) y con la herramienta zoom se visualiza el trazado en color rojo; f) En el cuadro rojo se encuentra el número de pixeles del área total verde y se saca el área total rojo para proceder a sacar el porcentaje del daño. se realizó durante la marea alta, desde una embarcación de madera, en el interior del estero (Kauffman, Donato \& Adame 2013); en cada uno de los transectos, y de manera aleatoria, durante la marea alta, las copas de los manglares quedan expuestas, y solo se puede acceder a las mismas desde la canoa en el estero.

\section{Daño foliar}

Las hojas de Rhizophora harrisonii, fueron registradas en formato digital en campo y su posterior manejo en escritorio, se identificó de manera previa el tamaño referencial individual a partir de la superficie foliar, se fotografiaron las hojas colectadas con una resolución de 720 pixeles, a distancias de hasta $5 \mathrm{~cm}$ las imágenes fueron digitalizadas con la versión Creative Cloud del programa Adobe Photoshop Extended (Fig. 3).

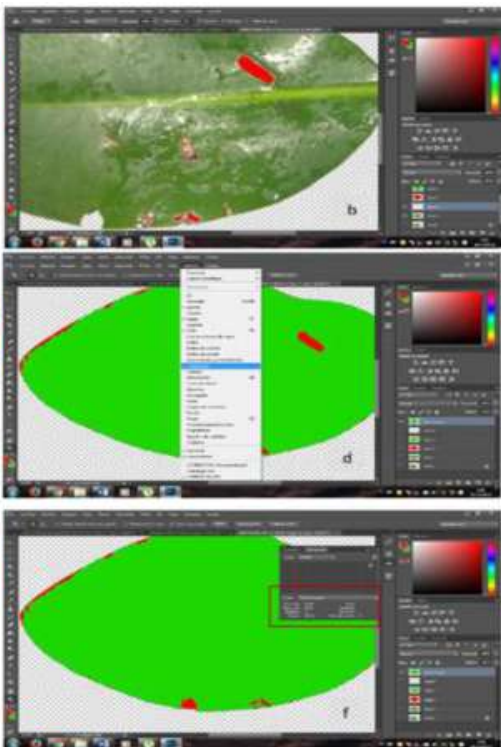




\section{Tamaño de las estomas}

La observación de los mismos se realizó con un microscopio invertido Marca Motic AE 31. Se midió la apertura estomática con la cámara MOTICAN N480 y el software Motic Image Plus serie S653711 para la captura de las imágenes.

El campo de observación fue de 10x y 40x, considerando los cinco campos del cubre objeto cuya medida aproximada es de $24 \mathrm{~mm}^{2}$. Se extrajeron los datos numéricos desde el software y la conversión a una Tabla de Excel para la obtención de los mismos.

\section{Extracción del índice estomático}

El índice estomático (IE) se calculó utilizando la fórmula siguiente (Wilkinson, 1979):

$$
\mathrm{IE}=[\mathrm{E} /(\mathrm{E}+\mathrm{CE})] \times 100
$$

dónde: E: número de estomas.

$\mathrm{CE}$ : número de células epidérmicas.

Indicador: índice estomático en las hojas de Rhizophora harrisonii colectadas en tres transectos de $100 \mathrm{x}$ $0.50 \mathrm{~m}$ en la Isla Trinitaria frente a los principales puertos de Guayaquil.

\section{Determinación del $\mathrm{pH}$}

La determinación del $\mathrm{pH}$ se hizo para las dos épocas, seca y lluviosa, las muestras analizadas fueron colectadas frescas en cada uno de los transectos. El tratamiento previo para la obtención del
$\mathrm{pH}$ consistió en el secado en estufa a $60^{\circ}$ $\mathrm{C}$, luego se procedió a la trituración de las mismas, hasta obtener polvo de hojas, se pesó dos gramos disueltos en $50 \mathrm{ml}$ de agua ultra destilada, se midió con un peachímetro marca Fisher Scientific modelo: ACUMET P61 un total de 180 muestras.

\section{Estadístico}

Para el procesamiento estadístico se utilizó el software Statgraphics Centurion XVI.I portable para los cálculos de regresión lineal, y la aplicación del estadístico ANOVA Simple de una vía para la comparación de las medias, las que se validaron con el test Kruskal Wallis, que se fundamenta en que los datos provienen de una población no paramétrica.

\section{Resultados}

En la Isla Trinitaria, zona influenciada por el Puerto de Guayaquil, las hojas de Rhizophora harrisonii, presentan escasa turgencia, la superficie foliar llena de hollín (Fig. 4), esto se evidencia y visualiza en la época seca, más no en la época lluviosa, ya que el agua limpia las mismas.

Los daños por acidificación o deposición seca pueden ser estimados solo en la Isla Trinitaria, donde se aprecia el color de las hojas de manglar con tonalidades verde claro con tendencia al amarillo predominantemente en el transecto 1(3), además de los daños por herbivoría en el transecto 1 (1-3), se presentaron de manera generalizada en 


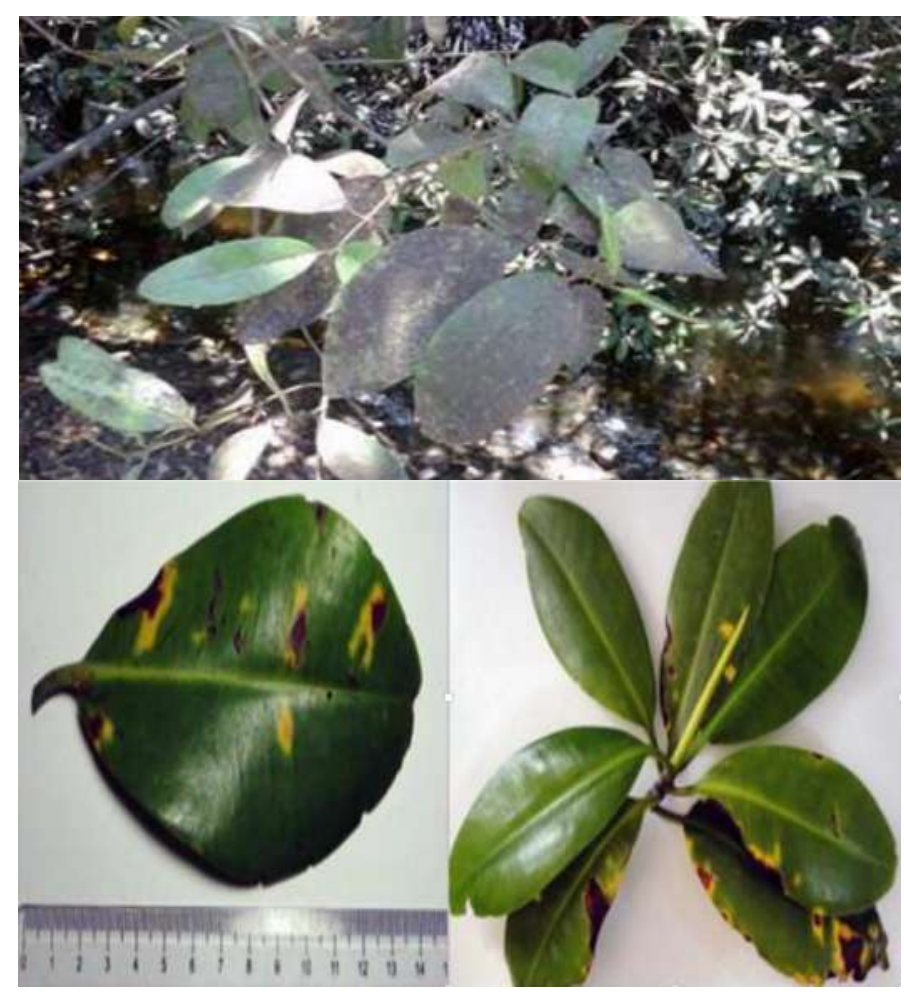

Figura 4. Recuadro superior hojas de mangle cubiertas de hollín en la zona de actividad portuaria, imágenes inferiores izquierda y derecha con clorosis (pigmentación amarilla), y necrosis (pigmentación café ó marrón) en hojas de Rhizophora harrisonii.

las hojas de Rhizophora harrisonii. Las medias porcentuales de daño foliar durante la época lluviosa no son significativamente diferentes, en cambio en la época seca el Transecto 1 presenta diferencias significativas en relación al 4.

Durante la época seca, las hojas presentaron daños como necrosis, clorosis (Fig. 5) y ramoneo provocado

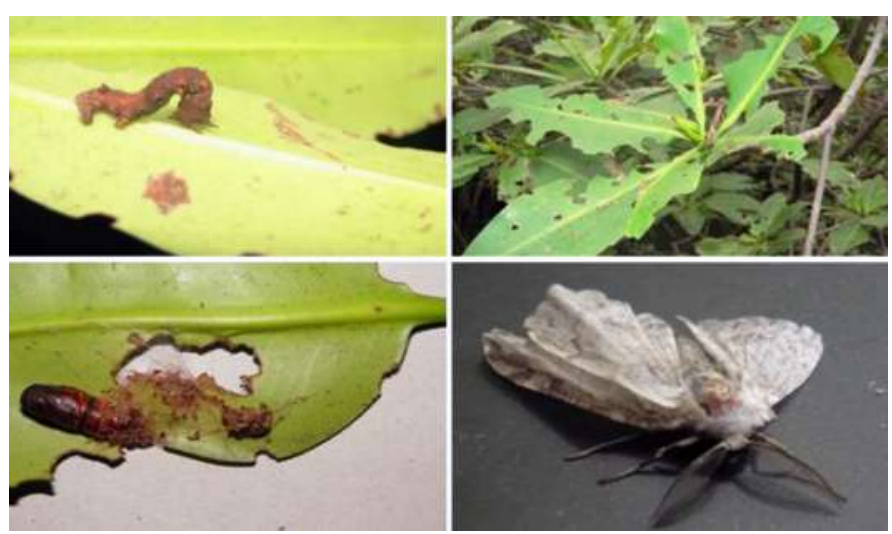

Figura 5. Imágenes superior e inferior izquierda larva de Thyrinteina arnobia Stoll, ramoneando y estadio de crisálida en una hoja de Rhizophora harrisonii, cuadrante superior e inferior derecho hojas afectadas, e individuo de Thyrinteina arnobia Stoll, respectivamente en la Isla Trinitaria. 

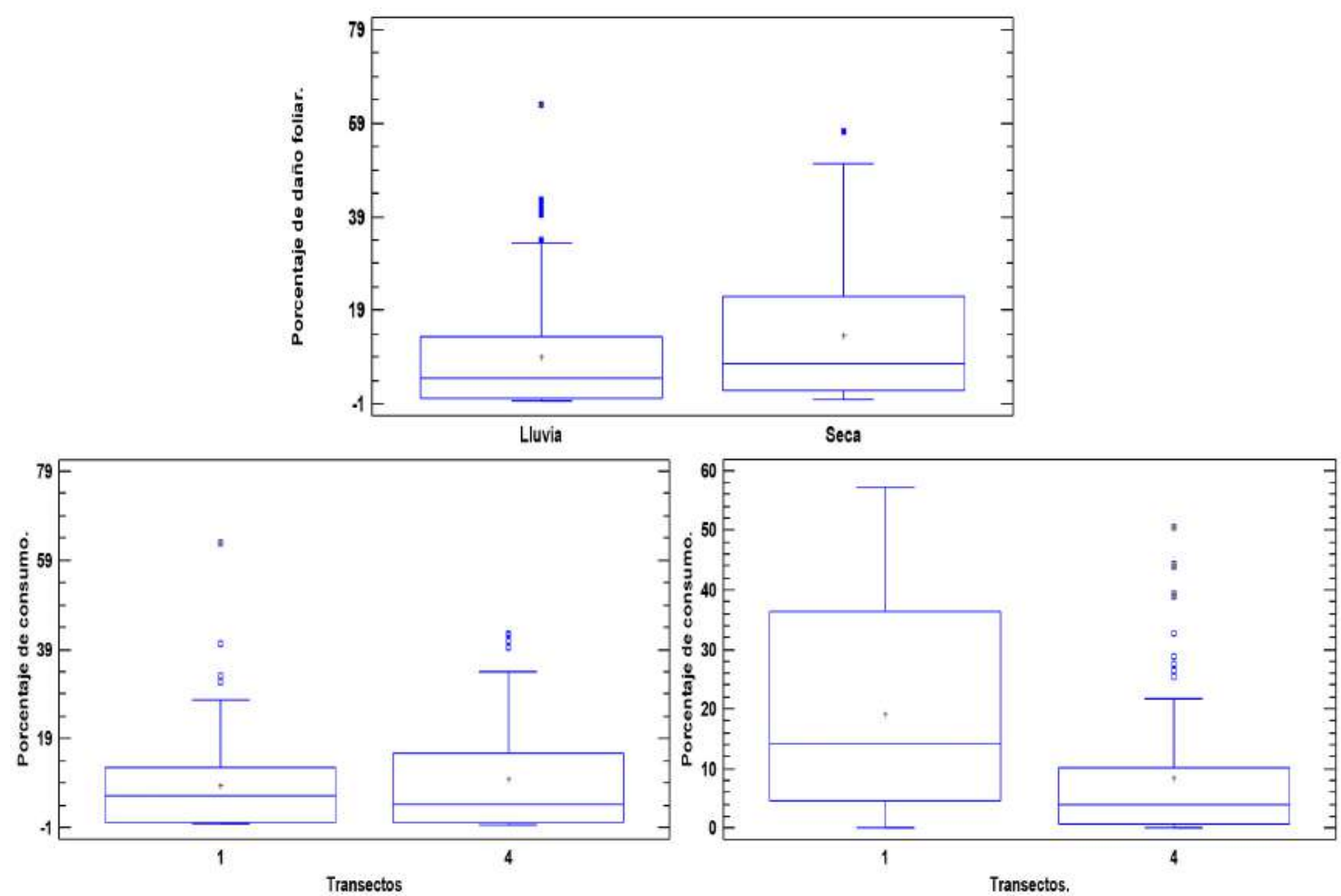

Figura 6. Medias del porcentaje de daño foliar en las hojas de Rhizophora harrisonii durante la época seca y lluviosa.

por Tyrinteina arnobia Stoll de la familia Geometridae (Fig.6), con porcentajes de $4 \%$ hasta el $15 \%$ entre los transectos 1 y 2 respectivamente, el transecto 1 presenta el mayor porcentaje de daño con valores del 39\% y en el control (4) los daños son del 5\%; (Fig. 6).

De acuerdo con el test de Kruskal Wallis, el p-value 0,0012603 es significativamente diferente entre los sitios de estudio (a), para el caso de la estacionalidad el $p$-value es de 0,68514 , lo que demuestra que no hay diferencias significativas de las medianas, para los sitios de estudio, Isla Trinitaria (1), e Isla Chupador Chico (4), durante la época lluviosa (b), y para la época seca (c), las diferencias son estadísticamente significativas ya que el p-value 2,3940E-7 con un $95 \%$ de confianza.
La regresión lineal obtenida fue igual a 1 para todos los datos del porcentaje foliar generados por Photoshop Extended. Con el uso del programa se puede aseverar la ubicación de las mismas en las ramas de los árboles en razón de que los valores promedios determinados para las hojas superiores están entre 6-8 cm y las más grandes entre 12 a $18 \mathrm{~cm}$.

La época seca y la lluviosa son parámetros físicos que marcan la diferencia entre las plantas, el índice estomático es superior durante la época seca, no así en la lluviosa, de igual manera la abundancia de las células epidérmicas es el doble en la época lluviosa, las mediciones de la apertura estomática variaron de acuerdo a la época (Fig. 7) lo cual refleja medias 
significativas diferentes entre los transectos (1-3) y el control, los valores de apertura estomática de la época seca son de $1.67 \times 10^{-14}$ ( Tabla 2).

La sensibilidad de las estomas a la humedad atmosférica se da por las diferencias entre el contenido de vapor del aire y el de los espacios intercelulares supera un nivel crítico. Un gradiente elevado tiende a inducir oscilaciones en la apertura y el cierre, con una periodicidad de 30 minutos aproximadamente.

Las hojas de Rhizophora harrisonii responden a una clasificación epistomática

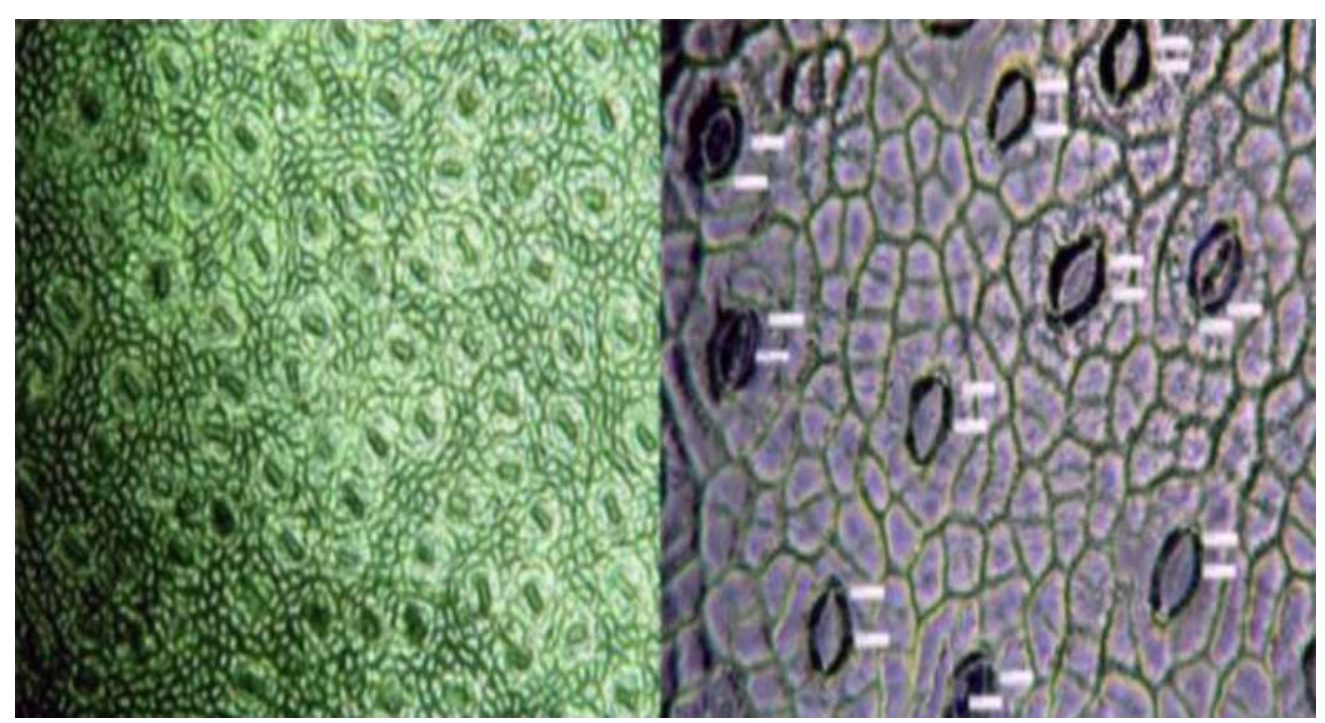

Figura 7. Estomas de Rhizophora harrisonii 10x y 40x.

Tabla 2.

Densidad e índice estomático y pH de Rhizophora harrisonii durante la época seca y lluviosa

\begin{tabular}{|c|c|c|c|c|c|}
\hline \multicolumn{6}{|c|}{ Epoca seca } \\
\hline & $\begin{array}{c}\text { No. } \\
\text { Estomas }\end{array}$ & $\begin{array}{l}\text { No. Celulas } \\
\text { epiderminc }\end{array}$ & $\begin{array}{c}\text { Indice } \\
\text { estomatico }\end{array}$ & $\begin{array}{r}\text { Apertura } \\
\text { estomatica }\end{array}$ & $\mathbf{p H}$ \\
\hline Transecto 1 & 5 & 108 & 4,08 & $2,19 \mathrm{E}-14$ & 5,3113 \\
\hline Transecto 2 & 6 & 112 & 5,39 & $1,86 \mathrm{E}-14$ & 4,9046 \\
\hline Transecto 3 & 5 & 147 & 3,74 & $2,26 \mathrm{E}-14$ & 5,4063 \\
\hline Control & 4 & 122 & 3,9 & $2,21 \mathrm{E}-14$ & 5,3745 \\
\hline \multicolumn{6}{|c|}{ Epoca lluviosa } \\
\hline Transecto 1 & 4 & 213,33 & 2,0076 & $2,54 \mathrm{E}+00$ & 4,9446 \\
\hline Transecto 2 & 5 & 205,12 & 2,9876 & $1,73 \mathrm{E}+00$ & 4,9046 \\
\hline Transecto 3 & 3 & 255 & 1,5762 & $2,15 \mathrm{E}+00$ & 5,0946 \\
\hline Control & 9 & 162 & 2,2466 & $6,98+05$ & 5,1607 \\
\hline
\end{tabular}

123

INVESTIGATIO No. 13, marzo 2020, pp. 115-130,

ISSN: 1390 - 6399・ISSN-e: 2602 - 8336 
(Fig. 8), en atención a la distribución de las estomas en la epidermis adaxial en la cara haz o cara superior, por el número de células epidérmicas diferenciadas oclusivas y su ubicación respecto a estas, son ciclosíticos, por tener células anexas en número mayor a cuatro, se disponen en ciclos alrededor de la estoma.

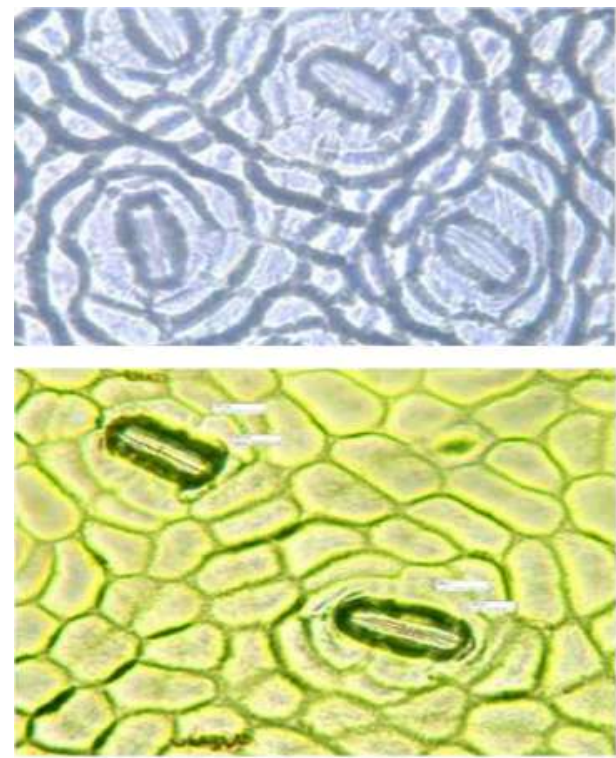

En la época lluviosa las estomas están más abiertos que en la época seca, sus aperturas varían entre $6.98 \times 10^{-05} \mathrm{y}$ $1.861 \times 10^{-14}$ respectivamente. El índice estomático es más bajo que en la época seca y hay mayor número de estomas $\mathrm{y}$ menor número de células epidérmicas (Fig. 9).

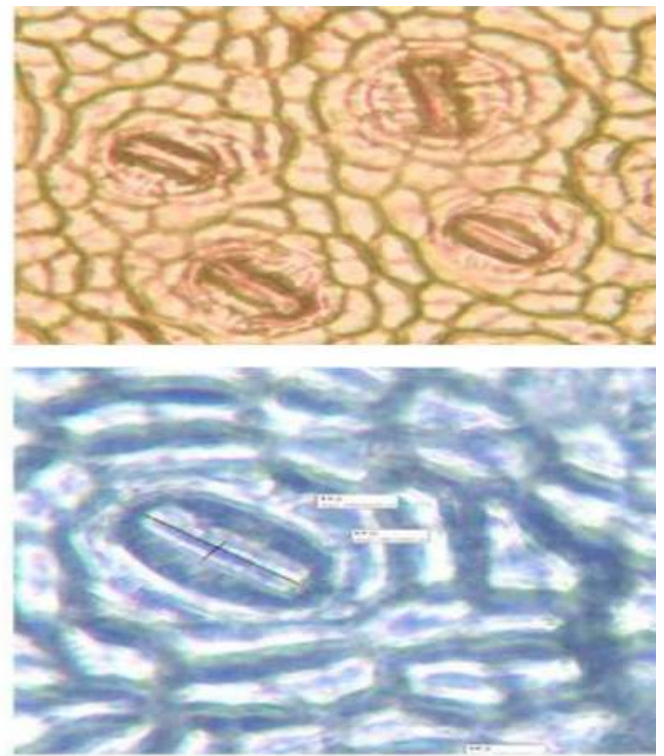

Figura 8. a) Estomas ciclosíticos de Rhizophora harrisonii, 40 X, a) Transecto 1, b) transecto 2, c) transecto 3, y d) Control.

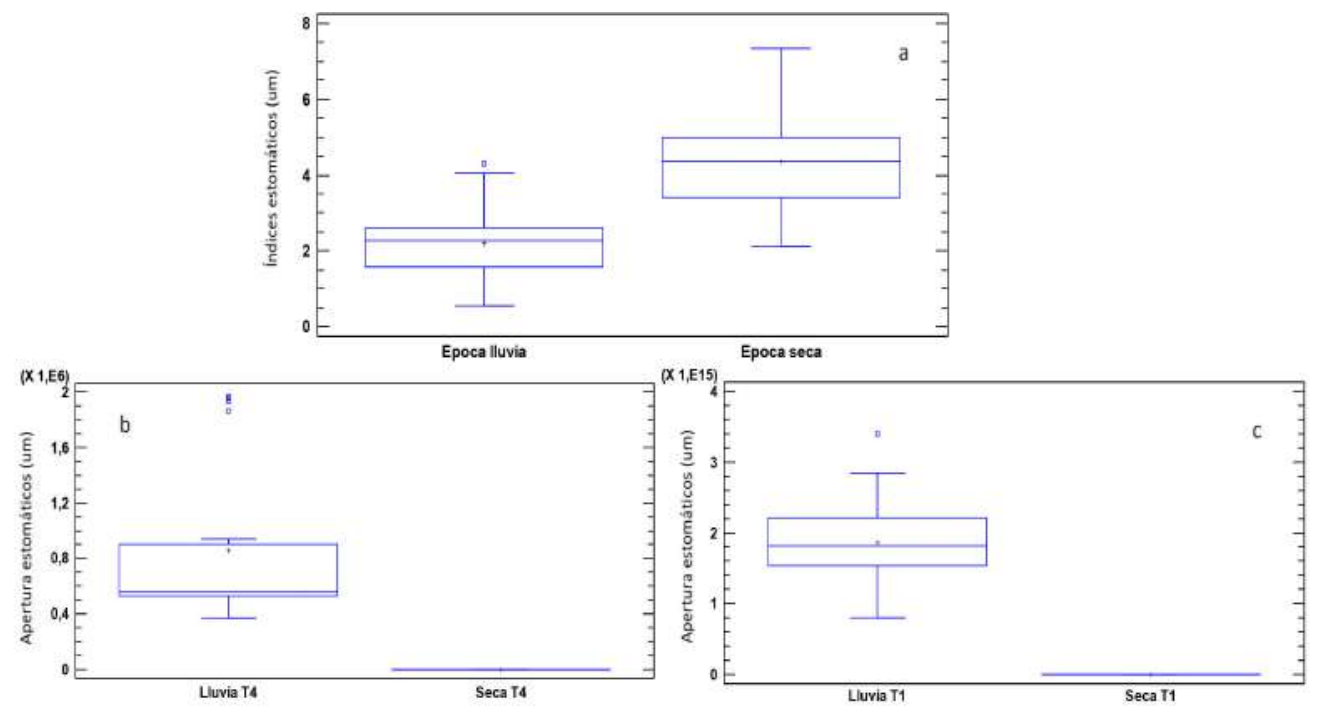

Figura 9. Índice y apertura estomática en um de acuerdo con las épocas lluviosa y seca en cada uno de los transectos 1(Isla Trinitaria) y 4 (Isla Chupador Chico); a) p-value 1,12328E-9; b y c) El p-value para la apertura en los transectos 1 y 4 es de 6,1016E-10 y 6,16324E-10 respectivamente. 


\section{Discusión}

De acuerdo con (Atala, Saldaña \& Navarrete 2012), destacan que el control de la pérdida de agua y la regulación térmica se logran con el reconocimiento de la apertura y cierre de los estomas, este último es asociado con el estrés hídrico, lo que provoca la pérdida de la turgencia en las hojas, las mediciones de la apertura estomática variaron de acuerdo a la época, lo cual refleja medias significativamente diferentes entre los transectos y el control, los valores de apertura estomática de la época seca fueron de $1.67 \times 10^{-14}$, significativamente menos aperturados que los de la Isla Chupador Chico.

En el caso de la vegetación una adecuada humedad relativa ambiental puede favorecer la absorción de los contaminantes gaseosos por estimular la apertura de los estomas (Martineau \& Novello 2004). También las deficiencias nutricionales y otras agresiones ambientales pueden contribuir a agravar la respuesta del organismo frente a la contaminación. En la época lluviosa los estomas están más abiertos que en la época seca, y varían entre $6.98 \times 10^{-05}$ y $1.861 \times 10^{-14}$ respectivamente. El índice estomático es más bajo que en la época seca y hay mayor número de estomas y menor número de células epidérmicas, ecológicamente esto significa que las plantas están respondiendo a estrés ambiental en la Isla Trinitaria, así como los factores antrópicos presentes, producto de la actividad naviera, en cambio en la Isla Chupador Chico las estomas tanto para la época seca como lluviosa están significativamente abiertos.

Por las estomas penetran un sinnúmero de elementos atmosféricos, producto de la reacción de hidrocarburos con el agua, formando ozónidos que se descomponen creando agua oxigenada $\left(\mathrm{H}_{2} \mathrm{O}_{2}\right)$ que penetran por estos y alteran el funcionamiento celular (Esau et al., 2008). Las células epidérmicas, en especial las oclusivas, toman grandes cantidades de agua, mientras que las mesofílicas se deshidratan (Esau et al., 2008). Fuglestvedt et al. (2010) señala que son relevantes los compuestos de $\mathrm{S}$ y $\mathrm{N}$ que provocan acidificación $\mathrm{y}$ eutrofización de los ecosistemas naturales y los cuerpos de agua dulce. Las hojas se hacen quebradizas y desarrollan manchas cloróticas. Un importante contaminante, el anhídrido sulfuroso $\left(\mathrm{SO}_{2}\right)$, solo o junto con el ozono, causa clorosis y enanismo de árboles (Esau et al., 2008). El $\mathrm{pH}$ de las hojas siempre se mantuvo entre 4,90 y 5,37 en las dos épocas, pero en la Isla Chupador Chico siempre es menos ácida, 5,37 en la época seca y 5,16 en la lluviosa.

Los hallazgos de Filoso, Williams, \& Melack (1999), se relacionan con este estudio porque demuestran como las plantas reaccionan a las condiciones ambientales atmosférica, sean estos depósitos de material particulado ultrafino (PUF) u hollín, y pueden ser atribuibles a factores externos como el intercambio gaseoso y la presencia de hollín (Casson, Casson \& Gray, 2008) factores que las obligan a tornarse resilientes, lo que coincide con las 
variaciones de espacio y tiempo que se despliegan en el dosel del bosque de Río Negro en Brasil, (Filoso, Williams \& Melack 1999), quienes demostraron que la deposición seca y el intercambio en el dosel son procesos relacionados con las características biológicas de los bosques, desde los tejidos internos de las plantas y la superficie de las hojas (Lawrence \& Fernandez, 1993) y (Lovett et al., 1996), en el caso de la Isla Chupador Chico las hojas se presentaron turgentes en los tres transectos, pero quebradizas $\mathrm{y}$ despigmentadas en la Isla Trinitaria, además de ser arboles achaparrados de no más de ocho metros de altura en esta última.

El $\mathrm{SO}_{2}$ agente contaminador importante del aire ocasionan daños no perceptibles a simple vista a las plantas (Kondo y Sugahara, 1978 en Cerón, et al., 2016). El grado de daño visible como clorosis y necrosis, varía entre especies, incluso si la exposición a $\mathrm{SO}_{2}$ se da en condiciones de concentración baja (Thomas 1961), (Zimmermann et al., 2008) también los describe como depósitos secos o húmedos a partir del traslado local o regional de los aerosoles lo que está directamente relacionado con la calidad de las hojas de manglar. Se acepta generalmente que las lesiones dependen del $\mathrm{SO}_{2}$ por lo menos en parte en la entrada del gas a través de los estomas (Taylor 1973 en Cerón et al., 2016). (Quevedo et al. 2018) indico que la distribución de las cargas críticas de azufre en el Puerto de Guayaquil y el Estuario Interior del Golfo de Guayaquil, tienen una distribución homogenea, a partir de lo cual relacionó que los procesos de necrosis y clorosis hallados en la Isla Santana y Trinitaria del área Natural El Salado son producto de la actividad portuaria que se desarrolla en el sitio.

Jumbo (2000) reportó a Thyrinteina arnobia Stoll de la familia Geometridae que se alimenta de hojas de manglar en la ciudad de Guayaquil, y Cornejo y Bonifaz, (2006) describen a Cocotripes que se alimenta de plántulas de mangle en el Ecuador, la presencia de Thyrinteina arnobia Stoll, se registra por segunda ocasión después de 16 años, la cual ramonea las hojas jóvenes y posteriormente se encapsula en las mismas, esta especie no se registró en la Isla Chupador Chico, donde el consumo foliar es significativamente diferentes en relación a la Isla Trinitaria 40\%. El 5\% reportado para la Isla Chupador Chico corresponde a otros tipos de herbívoros que no se presentan como plaga.

\section{Conclusiones}

Los manglares de la Isla Trinitaria y de la Isla Chupador Chico varían significativamente respecto a los factores biológicos, temporoespaciales, ambientales y antrópicos que influyen en la misma.

El $\mathrm{pH}$ es un indicador del grado de acidez de las hojas sea por las concentraciones de las sales, por tratarse de una especie eurohalina, el intercambio gaseoso que se da a través de las estomas y la importancia de su apertura que varía de acuerdo a la estacionalidad y a la calidad del medio donde se encuentra 
Rhizophora harrisonii, siendo la Isla Chupador Chico un sitio con régimen de conservación y el único referente para ser comparado con la Isla Trinitaria, se puede deducir que el manglar en este sitio se encuentra en condiciones óptimas.

Se puede considerar a Thyrinteina arnobia Stoll como un bioindicador sobre la calidad del manglar el cual lo utiliza como hospedero, además que su comportamiento es cíclico ya que fue reportado por primera vez hace 16 años, y a partir de esto se sigue observando su presencia con brotes esporádicos que reflejan un comportamiento de plaga, respecto a lo cual no se ha realizado un estudio que corrobore los picos más extremos de su presencia en los manglares de la ciudad de Guayaquil.

La ausencia de Thyrinteina arnobia Stoll en la zona de control se puede deber a varios factores físicos y biológicos:

Físicos:

- La dirección de los vientos posibilita que la especie se desplace con facilidad en dirección noreste.

- Las concentraciones de $\mathrm{CO}^{2}$ pueden estar colaborando en la presencia del mismo en la Isla Trinitaria.

\section{Biológicos:}

- Los manglares de la Isla Trinitaria están afectados por varios factores como la compactación del suelo, el limite urbano, y los puertos. En cambio, la Isla Chupador Chico es un área natural protegida.

- Thirinteina arnobia Stoll, puede ser parte de la red trófica en la Isla Chupador Chico por eso su presencia no logró ser registrada. En la Isla Trinitaria puede que no haya depredadores para este insecto por eso su presencia es significativa.

La época seca y lluviosa como factor físico ambiental nos permite observar manifestaciones morfológicas de las plantas ligadas al proceso de fotosíntesis como elemento vital en su supervivencia. Las marcadas diferencias entre época seca y lluviosa incide en el follaje de Rhizophora harrisonii en el Puerto de Guayaquil, sumado a las emisiones de gases provenientes de la actividad naviera, industrial y urbana, aerosoles que se adhieren al dosel de la vegetación bajo el fenómeno de deposición seca.

Se considera que la época seca es la más extrema para Rhizopohora harrisonii en la Isla Trinitaria, por presentar alto daño foliar del $40 \%$ para los transectos 1-3, bajo número de células epidérmicas, alto índice estomático, y baja apertura estomática y el pH ácido de 4.9 en sus hojas, en comparación con la zona de control "Isla Chupador Chico".

La época lluviosa es una oportunidad para la regeneración de las hojas de Rhizophora harrisonii los daños son del $15 \%$, similares entre los transectos, no se registraron plagas para ésta época en ninguno de los sitios de estudio, los daños son atribuidos a la carencia o incremento de elementos minerales o deposiciones húmedas (rainout), que generan clorosis y necrosis. 


\section{Agradecimientos}

Srtas. Samanta Rojas y María Jaramillo, digitadora de las muestras de la carrera de diseño Gráfico, al Dr. Washington Cárdenas Director del Laboratorio de Biomedicina de la ESPOL, y al Dr. Willan Revelo del Instituto Nacional de Pesca.

\section{Referencias}

Atala, Cristian, Alfredo Saldaña, and Eduardo Navarrete. 2012. "Stomatal Frequency and Gas Exchange Differs in Two Blechnum Species (Pteridophyta , Blechnaceae) with Contrasting Ecological Breadth." Gayana bot 69(1): 161-66.

Bodner, Florian et al. 2010. "Caterpillars and Host Plant Records for 59 Species of Geometridae (Lepidoptera) from a Montane Rainforest in Southern Ecuador." Journal of Insect Science 10(67): 1-22.

Carvajal Raúl, Salas Jaime, Zambrano Geovanny \& Bohorquez Carla. 2012. "Ficha Informativa de Los Humedales de Ramsar (FIR )." : 1-17.

Casson, Stuart, Stuart Casson, and Julie E Gray. 2008. "Influence of Environmental Factors on Stomatal Development." : 9-23.

Cerón, R.M. et al. 2009. "Effects of Simulated Acid Rain on Tropical Trees of the Coastal Zone of Campeche, Mexico." WIT Transactions on Ecology and the Environment 126.

CLIRSEN, and PMRC. 2006. “Actualización Del Estudio Multitemporal de Manglares, Camaroneras y Áreas Salinas En La Costa Continental Ecuatoriana Al Año 2006." 1: 13.
Dobbs, C. et al. 2018. 69 Unasylva 250 Beneficios de La Silvicultura Urbana y Periurbana. www.fao.org/forestry/unasylva.

Ecobiotec. 2012. Caracterización Biológica Del Estero Salado En Ramales Con Diferentes Tipos de Desarrollo Urbano Informe Final Del Inventario de Flora Y. Guayaquil, Ecuador.

Esau, Katherine, Evert y F. Ray (2008). Anatomía vegetal. Editorial Omega. 3era Edición ISBN: 978-84-282-1443-8. 640 Págs.

Filoso, Solange, Michael R. Williams, and John M. Melack. 1999. "Composition and Deposition of Throughfall in a Flooded Forest Archipelago (Negro River, Brazil).” Biogeochemistry 45(2): 169-95.

Fuglestvedt, J. S. et al. 2010. "Transport Impacts on Atmosphere and Climate: Metrics." Atmosphernesic Environment 44(37): 4648-77.

Giraldo, Jose, and Juan Ramírez. 2009. "Niveles de Herbivoría Para El Género Miconia En Tres Tipos de Coberturas Vegetales Altoandinas En Colombia." Revista Forestal Mesoamerica Kurú 6(16): pág. 4-16.

Guerrero, Natalia Rincón, Manuel Andrés Olarte Quintero, and Juan Carlos Pérez Naranjo. 2012. "Determinación Del Área Foliar En Fotografías Tomadas Con Una Cámara Web, Un Teléfono Celular o Una Cámara Semiprofesional." Revista Facultad Nacional de Agronomía 65(1): 6399-6405.

Kauffman, J. Boone, Daniel Donato, and María Fernanda Adame. 2013. "Protocolo Para La Medici\&amp;Oacute; $n$, Monitoreo y Reporte de La Estructura, Biomasa y Reservas de Carbono de Los Manglares." Documento de Trabajo 86: 117. http://www.cifor.org/library/4386/protoc olo-para-la-medicion-monitoreo-y-report e-de-la-estructura-biomasa-y-reservas-de -carbono-de-los-manglares. 
Lawrence, G. B., and I. J. Fernandez. 1993. “A Reassessment of Areal Variability of Throughfall Deposition Measurements." Ecological Applications 3(3): 473-80.

Martineau, Robert J., and David P. Novello. 2004. The Clean Air Act Handbook.

Minchinton, Todd E, and Mia Dalby-ball. 2001. "Frugivory by Insects on Mangrove Propagules: Effects on the Early Life History of Avicennia Marina." : 243-52.

Pentón, Gertrudis, W Torres de la Noval, and G Martín. 2006. "Estimación Del Área Foliar a Partir de Observaciones Morfológicas Convencionales En Morus Alba Var. Acorazonada." Pastos $y$ forrajes 29(3): 247-53.

Quevedo, O et al. 2018. "Referential Seasonality of Critical Loads of Sulfur on Rhizophora Harrisonii in the Port of Guayaquil." Wseas 15: 24-34

http://www.wseas.org/multimedia/journa ls/biology/2018/a085908-050.php.

Robertson, A I, R Giddins, and T J Smith. 1990. 83 Oecologia Seed Predation by Insects in Tropical Mangrove Forests: Extent and Effects on Seed Viability and the Growth of Seedlings*.

Sandrini-Neto, Leonardo, Leonardo Hostin, Paulo Lana, and Franciane Pellizzari. 2007a. "Un Nuevo Método de Análisis Digital Para La Determinación de Los Niveles de Consumo Foliar." Investigaciones Marinas 35(1): 111-16.

Sandrini-Neto, Leonardo, Leonardo Hostin, Paulo Lana, and Franciane Pellizzari. 2007b. "Un Nuevo Método de Análisis Digital Para La Determinación de Los Niveles de Consumo Foliar." Investigaciones marinas 35(1): 1-6.

Senf, Cornelius, Rupert Seidl, and Patrick Hostert. 2017. "Remote Sensing of Forest Insect Disturbances: Current State and Future
Directions." Int J Appl Earth Obs Geoinformation 60(February): 49-60.

Zimmermann, Alexander et al. 2008. "SpatioTemporal Patterns of Throughfall and Solute Deposition in an Open Tropical Rain Forest." Journal of Hydrology 360(1-4): 87-102. 
